\title{
DESIGN INVESTIGATION ON FOOT DEFORMITIES WORKING FOOTWEAR
}

\author{
Nor Rofizah Johari ${ }^{1}$ \\ Department of Design \& Visual Communication, Politeknik Ibrahim Sultan, Malaysia. \\ (Email: joharinorro@gmail.com) \\ Khatijah Md Saad ${ }^{2}$ \\ Politeknik Ibrahim Sultan, Malaysia. \\ (Email: tiram37@hotmail.com)
}

Received date: 02-04-2018

Revised date: 29-04-2018

Accepted date: 15-12-2019

Published date: 15-12-2019

To cite this document: Johari, N. R., \& Md Saad, K. (2019). Design Investigation on Foot Deformities Working Footwear. Journal of Information System and Technology Management, 4(15), 41-47.

DOI: $10.35631 /$ jistm. 415004

\begin{abstract}
Footwear was planned to protect the feet from the environment. Choosing the right footwear based on foot conditions and requirements enabling to reduce the risk of injury, fast fatigue, and foot pains. Good footwear should provide stability to the joints of the foot and a foundation upon which the foot can function. The objective of this study is to provide information that will assist researchers and designers in identifying, designing and offering appropriate and better working footwear designs for those with foot deformities. Two identified workers from the footwear factory with congenital foot deformities participated in this prospective intervention study for over 12 months. An interview and a video on how the participant wears and walk with normal commercial shoes were recorded. The physical examination was also assessed including the footwear, feet, legs, and hips of the subjects. They were examined with a focus on the areas of deformities. Each leg has different shape and concerns. Hence, each footwear designed for those with foot deformities must be customized base on the factors of type of deformities, body size and the remaining skeletal structure and muscular. With proper modification, people who have foot deformities and unable to buy suitable footwear will be able to relieve the pain and at the same time increase the individual motivation in job satisfaction, motivation or enthusiasm to work and reducing levels of stress or emotional upset.
\end{abstract}

Keywords: Footwear, Foot Deformities, Customize

\section{Introduction}

Footwear is a compulsory work clothes accessory. Historically, footwear was planned to protect the feet from the environment, nowadays shoes became a powerful fashion objects in addition 
to providing protection. The type and styles of shoes are depending on working environment. Example, the casual type of shoes such as Oxford and Derby are suitable for white color worker and safety shoe with safety features are suitable for blue color worker.

Prior research indicates that footwear should be functioned to protect the foot, increase friction, provide foot stability, provide shock attenuation, treat foot deformities and provide a foundation for foot orthoses. Footwear should provide stability to the joints of the foot and a foundation upon which the foot can function, and the ergonomics is a key element for comfort, health and productivity. Therefore, the establishment of these relations may increase the employee motivation in job satisfaction, motivation or enthusiasm to work and reducing levels of stress or emotional upset. Despite of this, there were still industrial worker with foot deformities do not choose the right shoe for them. Selecting proper footwear may lead to long term health conditions.

\section{Literature Review}

Footwear definition according to Merriam-Webster Dictionary is wearing apparel (such as shoes and boots) that are worn on your feet. Footwear invention was devised to protect the feet from the environment. Shoes became a statement of fashion as time goes by in addition to providing protection. But somehow the components of the footwear should provide support to the foot (T. McPoil, 1988). Hence, good basic anatomic information should be known by footwear designers that should consider properly foot shape and internal structure for developing "fit" and "healthy" shoes (Krauss et al. 2011; Mickle et al. 2010). Long before, a part of being a fashion accessory, footwear also can be an alternative way to treat foot deformities. Prior research stated that the modified last often being used to treat metatarsus adductovarus (Fig. 1). In 2015, Jawish stated that only a short time is needed to improve deformities like metatarsus adducts right after birth.
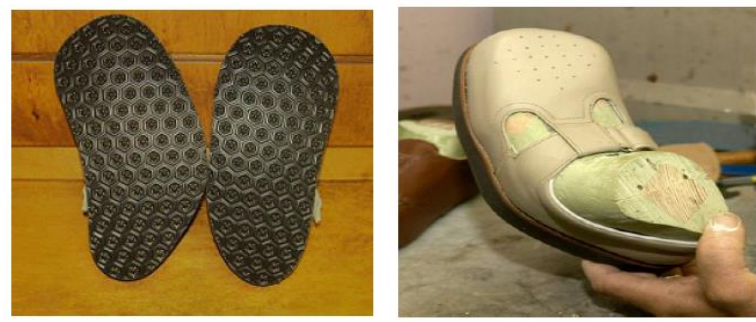

Figure 1: Deformities Custom Shoe

Source: http://www.alvarosorthopedicfootwear.com/custom_Made_Ortho_Shoes.php

The characteristics of a footwear has been discussed in many years. In a review paper by Nigg (2005), the research is divided into three sections, past, present and future. It is found that the three sections have a significance outcome where comfort was established to become important variables. To allow more objective measure of footwear quality, Barton, Bonanno and Menz (2009) have devised six items of footwear characteristic. (Fig.2). The foot definition according to Merriam-Webster Dictionary is the part of the leg on which animal or person stands and moves: the part of the leg below the ankle. Foot and ankle in the human body is work together to provide balance, stability, movement and propulsion. This complex anatomy consists of twenty-six bones, thirty-three joints, muscles, tendons, ligaments, blood vessels, nerves and soft tissues. The normal foot anatomy can be divided into three anatomic regions called hindfoot or rear foot, midfoot and fore foot. 
Foot deformities definition according to Merriam-Webster Dictionary is a condition in which part of the body does not have the normal or expected shape. Foot deformities is a disorder of the foot that can be divided into two categories. They are congenital and acquired.

Dr. Yong SuMei from Sime Darby Medical Center explained that the congenital foot deformities can be inherited or caused by extrinsic factors. Common congenital foot deformities include flatfoot, clubfoot, hook foot and various types of toe deformities such as extra toes, curly toe and syndactyly (web toes). Malaysia, in 1990, 5.6 per 1000 livebirths had congenital foot deformities (N, Y Boo, L, C Ong, 1990). Foot deformities were not only affected children but also adults. People will always find a solution to manage their footwear by using a various type of outsole, bars externally, arch support and put in the metatarsus pad (Mcpoil, 1988). According to Tax (1982), a stable foundation can be generated by using a suitable foot orthosis into an appropriate footwear.

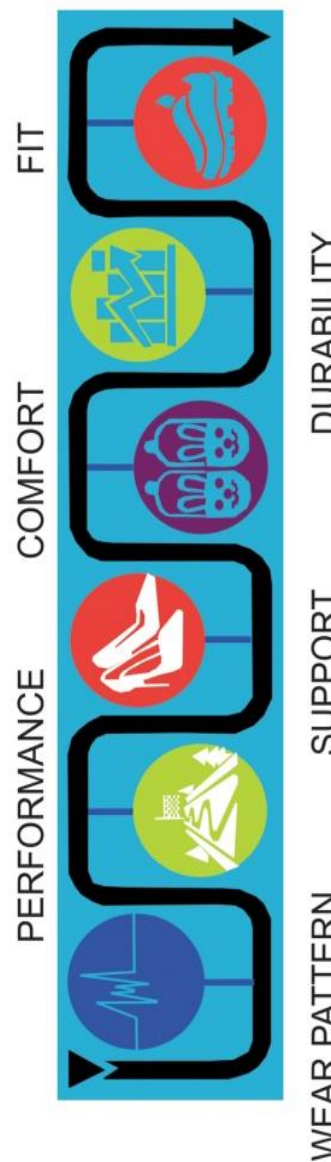

\begin{tabular}{|c|c|}
\hline \multicolumn{2}{|c|}{$\begin{array}{l}\text { Fit } \\
\text { Poorly fitting shoes have been linked to } \\
\text { falls, foot pain, pressure lesions in } \\
\text { patients with diabetes, neuromas, } \\
\text { corns and calluses and toe deformity in } \\
\text { older people. }\end{array}$} \\
\hline $\begin{array}{l}\text { - Age of Shoe } \\
\text { - Footwear type } \\
\text { - Materials (Upper) }\end{array}$ & $\begin{array}{l}\text { - Materials (Outsole) } \\
\text {-Weigth/Length Ratio }\end{array}$ \\
\hline \multicolumn{2}{|c|}{$\begin{array}{l}\text { Cushioning } \\
\text { Greater shock absorbing properties } \\
\text { (enhanced cushioning) in footwear have } \\
\text { been considered important in overuse } \\
\text { injury prevention. }\end{array}$} \\
\hline \multicolumn{2}{|c|}{$\begin{array}{l}\text { Motion Control Properties } \\
\text { Motion control properties of footwear are } \\
\text { considered important in falls prevention, } \\
\text { treatment of patients with diabetes and } \\
\text { rheumatoid arthritis and treatment of } \\
\text { musculoskeletal injuries. }\end{array}$} \\
\hline $\begin{array}{l}\text { General Structures } \\
\text { - Heel Height } \\
\text { - Last Shape }\end{array}$ & $\begin{array}{l}\text { - Fixation of upper to } \\
\text { sole } \\
\text { - Forefoot sole flexion } \\
\text { point }\end{array}$ \\
\hline \multicolumn{2}{|c|}{$\begin{array}{l}\text { Wear patterns } \\
\text { Wear patterns of footwear can provide } \\
\text { health professionals with some insight } \\
\text { into how an individual's foot is } \\
\text { functioning in the shoe and provide } \\
\text { guidance as to when a shoe has } \\
\text { become unsafe for requires } \\
\text { replacement. }\end{array}$} \\
\hline
\end{tabular}

Figure 2: Footwear Characteristic

Source: A Summarization from Barton, C. J., Bonanno, D., Menz, H.B. (2009). Development and Evaluation A Tool for The Assessment of Footwear Characteristic Journal of Foot and Ankle Research.

\section{Research Methodology}

The research was conducted using qualitative method. The research studies are devoted to two case study or subjects and the focus of the study is the data that is in the thick-lined box. Main data is divided into three sections, Primary Data, Secondary Data and Design Process. Both subjects are disabled blue colour worker with congenital foot deformities. Before the study 
embarked, researcher had gained an approval from the subjects. A design research framework was made as a guideline to ensure the research is on the right track. (Fig. 3).

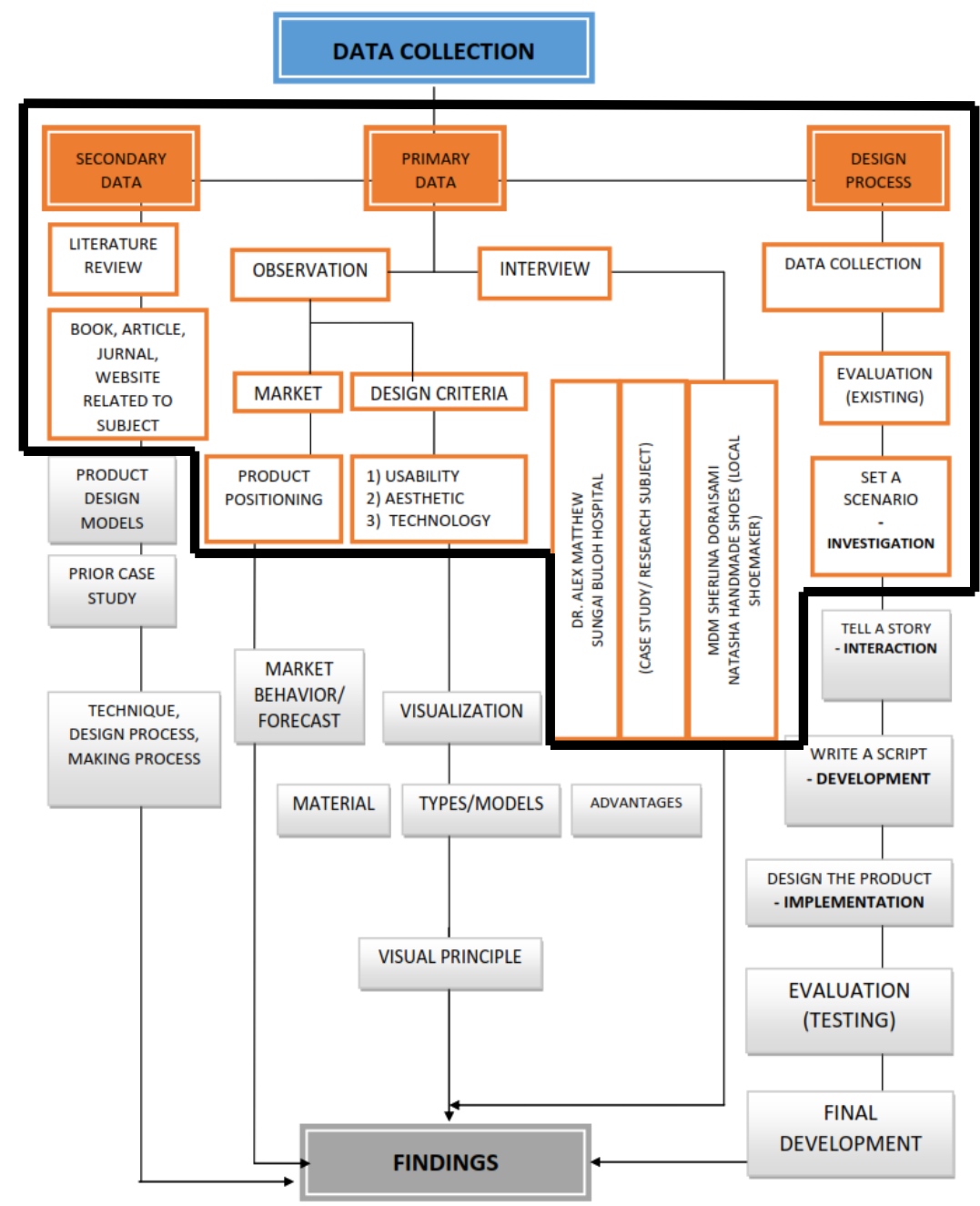

Figure 3: Design Research Framework

\section{Finding And Discussion}

Both case study subjects were not wearing a proper footwear although the working environment and the job specification required them to do various movements such as walking, standing, and sitting for a long time. Here is the primary investigation about subjects working footwear.

\section{Identify the Footwear (Subject A)}

Figure 4 below shows the case study's present safety footwear. While the shape of the right shoe looks fine, the left footwear had its quarter part (opening) wide open with a shoelace improperly fastened. It was because the wearer does not feel comfortable because the ankle of the leg is bigger and deformed. The right shoe however slanted forward because only the quarter part was frequently used during walking and sitting due to the right leg conditions. The outsole of the shoe shows the different sizes and state of wear on the heel, indicating heavy or excessive load and that will lead to other foot problems. The results of the study by Frey et al, was found that incorrectly fitting footwear was common and associated with forefoot disease and foot pain. 


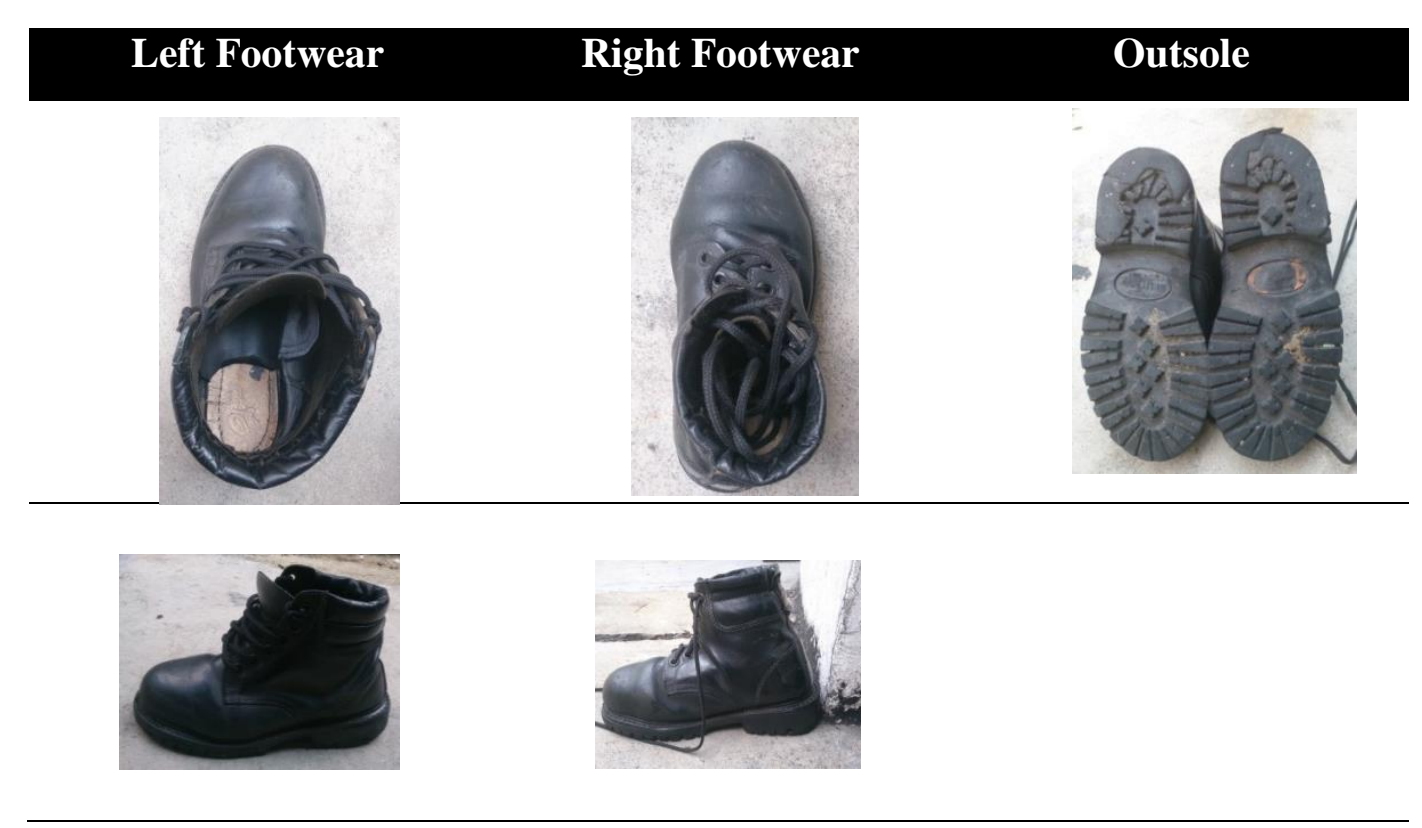

\section{Figure 4: The Shape and The Present Condition of The Footwear}

In order to wear the shoe, the subject also inserted the raised insole device for the stump for stability. A total of 18 pieces of $2.5 \mathrm{~mm}$ thickness cellulose board was glued together to get the ideal height of the leg. (Fig. 5). However, according to Active Health Management this kind of shoe modifications are merely considered to compensate for minor foot deformities and disabilities or leg shortening of less than 1.5 inches.

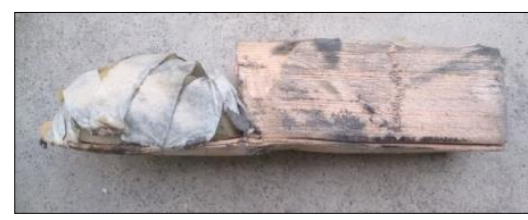

Figure 5: Raised Insole to Be Inserted Into the Shoe

\section{Identify the Foot Deformities}

This is an example of congenital foot deformities (Fig.6). Each leg has different deformities. It is multi-deformities such as talipes valgus, and less toes. According to medical dictionaries, talipes valgus refers to a permanent eversion of the foot, the inner side alone of the sol resting on the ground; it is usually combined with a breaking down of the plantar arch (left foot). Talipes is any of several deformities of the foot, especially those occurring congenitally. It may also be a non-traumatic deviation of the foot in the direction of one or two of the four lines of movement. 


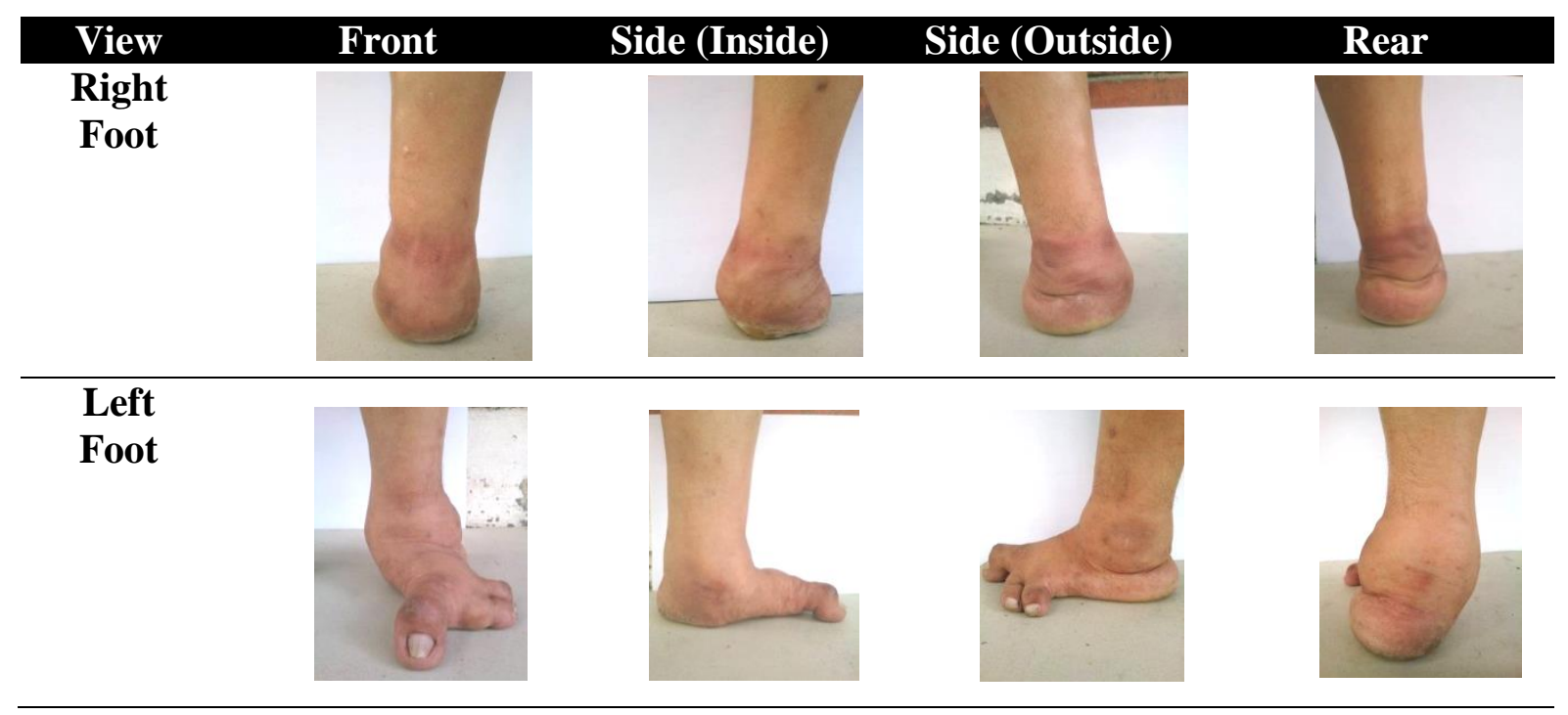

Figure 6: The Shape of Deformities and The Present Condition pf The Subject A

Figure 7 below shows another case study, Subject B. Subject B choose to wear a calf length boot due to his deformities. Subject B claimed that the calf length boot was the most suitable for him because the feet remain detached in the shoe as he walking. The boot with zipper also makes it easier to wear and open the shoes. However, he still unable to stand and walk properly without assistance.
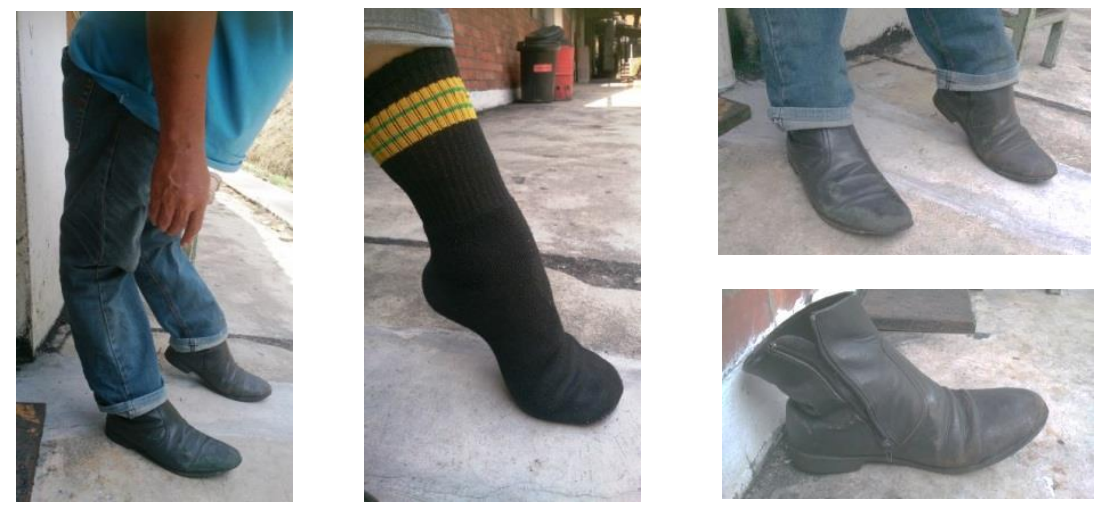

Figure 7: The Shape of Deformities and The Present Condition of Subject B

\section{Conclusion}

It is an essential to create awareness and knowledge to disabled people with foot deformities the important to choose the right footwear for them. 2 workers were selected, and they have different foot deformities. Depends on each deformity, proper shoe modification helps people who have foot problems and cannot buy appropriate prosthetics and orthotic devices to minimize the pain. Hence, each device designed for person with foot deformities must be customized based on the variety of factors including the affordability of the individual, beside the type of deformities, body size and the remaining skeletal structure and muscular. Like a thumbprint, foot deformities also different from one person to another. It is recommended for a future works to consider the use of $3 \mathrm{D}$ scanner to get the $360^{\circ}$ image of deformities foot. The result would be more accurate (Balasanker, 2014). The respondent is encouraged to take an $\mathrm{x}$ ray test so that the problem or the deformities can be easily identified by the medical 
practitioners. The designer also suggested to work closely together with a certified prosthetist and orthotist to encourage more solutions in footwear design.

\section{References}

Balasanker et. al. (2014). Design Footwear \& Braces For Children With Clubfoot Deformity. 9th International Shibori Symposium, China.

Barton, C.J., Bonanno, D., Menz, H.B. (2009). Development and Evaluation A Tool for The Assessment of Footwear Characterist. Jounal Of Foot and Ankle Research.

Caravaggi et. al. (2016). In Shoe Pressure Measurements During Different Motor Tasks While Wearing Safety Shoe: The Effect of Custom Made Insoles Vs. Fabricated And Off-TheShelf. Procedia Gait and Posture Vol. 50 page 232-238.

Frey C, Thompson F, Smith J, Sanders M, Horstman H. American Orthopaedic Foot and Ankle Society Women's Shoe Survey. Foot Ankle 1993; 14:78-81

Jawish, R. (2015). Combined Double Tarsal Wedge Osteonomy and Transcuneiform Osteonomy For Correction of Resistant Club Foot Deformity (The Bean Shaped Foot). Journal of Children's Orthopaedics. Volume 9, Issue 2, Pp 169-170

Krauss et. al (2011). Sex Related Differences in Foot Shape of Adult Caucasians - Follow Up Study Focusing on Long and Short Feet. Ergonomics 2011; 54:294-300.

L. C Ong, N. Y Boo. (1990). Congenital Talipes in Malaysian Neonates Incidence, Pattern and Associated Factors. Singapore Med. J 1990; Vol 31: 539-542.

Mcpoil, T.G. (1988). Footwear. Physical Therapy Journal of the American Physical Therapy Association.

Menz et al. (2014). Rocker-Sole Footwear Versus Prefabricated Foot Orthoses for Treatment of Pain Associated with First Metatarsophalangeal Joint Osteoarthritis: Study Protocol for Randomised Trial. BMC Musculoskeletal Disorders, 15:86

Mickle kj et. al. (2010). Foot Shape of Older People: Implications for Shoe Design. Footwear Sci 2010; 2:131-9.

Muhammad Mahdi Abdul Razak et. al. (2015). Quality of Life Among Lower Limb Amputees in Malaysia. Pocedia Social and Behavioral Sciences 222 (2016) 450-457.

Nigg et al. (2005). Footwear Research-Past, Present and Future. University of Calgary, Canada.

Rome et. Al. (2013). The Effetcs Of Commercially Available Footwear on Foot Pain and Disability in People with Gout: A Pilot Study. BMC Musculoskeletal Disorders, 14:278.

Sullivan et. Al. (2015). Determinations of Footwear Difficulties in People with Plantar Heel Pain. Journal of Foot and Ankle Research, 8:40.

Tomassoni, D., Traini, E., Amenta, B. (2014). Gender and Age-Related Differences in Foot Morphology. Maturitas Journal, 421-427. 